\title{
The role of innovative policy in creating system services to support development of agri-food enterprises
}

\author{
Zofia Gródek-Szostak ${ }^{1, *}$ \\ ${ }^{1}$ Cracow University of Economics, 31-510 Kraków, Rakowicka 27, Poland
}

\begin{abstract}
One of the most important objectives of the innovation policy of both developed and developing countries is the development of national and regional innovation systems. These are institutions and skills that aim to introduce innovations increasing competitiveness of the economy and improving the quality of life in society. Maintaining economic growth based on building a knowledge-based economy requires increasing the economic potential, mainly through increasing productivity and innovation. What is important in creating the innovative potential of the Polish economy is the fact that the large size of the Polish market, combined with the low level of openness to trade isolates domestic companies from their international competition. Domestic markets products and services are among the least liberalized in the EU and OECD. Polish companies may be sufficiently profitable in the domestic market, and therefore the pressure to compete with their counterparts abroad through investments in innovation and $\mathrm{R} \& \mathrm{D}$, is lower. An important role in building an innovative economy is played by the business environment institutions providing specialized services to support the development of enterprises. Between these entities that are a part of the entrepreneurship support system in Poland, there are numerous organizational and competence links. The aim of this study is to determine the course of action for activities undertaken in the framework of innovation policy, which are aimed at creating system support for the development of the agri-food sector. The idea behind the study was to verify the hypothesis that the availability of the system services affects the increase of competitiveness, profitability, or viability and potential of the agri-food sector. The object of the study was a pilot service in the field of marketing and sales of products for micro and small companies in the agri-food processing industry. It was carried out based on the system project of the Polish Agency for the Development of Entrepreneurship (PARP), "Providing enterprises with access to new services of the National Service Network (KSU)," financed under Sub-measure 2.2.1 of the Operational Programme Human Capital 2007-2013.
\end{abstract}

\footnotetext{
* Corresponding author: grodekz@uek.krakow.pl
} 


\section{Introduction}

One of the most important objectives of the innovation policy of both developed and developing countries is the development of national and regional innovation systems, i.e. the system of institutions and skills to, e.g., introduce innovations, increase the competitiveness of the economy and improve the society's quality of life [1]. Maintaining economic growth based on building a knowledge-based economy requires increasing the economic potential, primarily through increasing the productivity and innovation of enterprises. In creating the innovative potential of the Polish economy, it is important that the significant size of the Polish market, combined with a low level of openness to trade exchange, isolates domestic enterprises from international competition. Polish domestic product and service markets are among the least liberalized in the EU and OECD. Since Polish enterprises can be sufficiently profitable on the domestic market, the pressure to compete with their counterparts abroad by leveraging investments in innovation and R\&D, is lower.

Business environment institutions providing specialized services to support the development of enterprises play an important role in building an innovative economy. There are numerous organizational and competence links between the entities that are part of the entrepreneurship support system in Poland.

The purpose of this study is to determine the course of actions undertaken as part of the innovation policy aimed at creating system services to support the development of the agrifood sector. The idea of the research was to verify the claim that the availability of system services affects the increase in competitiveness, profitability and potential of agri-food sector enterprises. The subject of the study was a pilot marketing and sales service for micro and small enterprises in the agri-food industry, implemented on the basis of the system project "Ensuring access of enterprises to new KSU services" by the Polish Agency for Enterprise Development (PARP), financed under Sub-measure 2.2.1 of the Human Capital Operational Program for the years 2007-2013.

\section{Methodology}

The purpose of the service was to increase the competitiveness, profitability or profitability and potential of clients of a pilot marketing and sales service for micro and small enterprises in the agri-food industry. The service was implemented following an application to the system project "Ensuring access of enterprises to new KSU services" by the Polish Agency for Enterprise Development (PAED), financed under Sub-measure 2.2.1 of the Human Capital Operational Program (OP HC) for the years 2007-2013. The obtained consulting and training was to help companies in the process of transition from the level of micro to small enterprise, and from the level of small to medium enterprise. The service was addressed to micro and small enterprises operating in the agri-food industry, running a in non-agricultural business based on an entry in the Central Registry and Information on Business Activities (CEIDG) or the National Court Register (KRS).

The research included enterprises operating in Poland, which were beneficiaries of the PARP system project in the years 2014-2015. The initial research was conducted in 2013, and the summary research in early 2016 (upon project completion). The results presented below refer to the support system offered by Business Environment Institutions (BEIs), and belong to the authors' research field, regarding the courses and effects of using public funds in providing institutional forms of support for enterprises that implement innovations.

Own research (opinion questionnaire) included 30 beneficiaries of the selected system activity of OP HC 2007-2013, offering support to enterprises through BEIs. The support in question comprised two components: 
1. Component I consisted of three stages

Stage I: marketing audit involving a detailed analysis of the client's market situation as the basis for building an individualized marketing plan,

Stage II: Strategic individual consulting, resulting in a marketing plan and 5 executive marketing programs, formulated as practical actions

Stage III: Assistance in implementing the marketing plan and executive marketing programs.

2. Component II - training in basic marketing, building a marketing plan in the agri-food industry, implementing the plan in one's enterprise and monitoring its implementation.

In its basic scope, the analyzed activity was to provide entrepreneurs operating in the Polish agri-food sector access to comprehensive, high-quality business services necessary from the point of view of innovative business. In 2015-2016, the analyzed research group used the support offered by one of the contractors selected in a competition run by the PAED, which mainly provides services to enterprises. The scope of this service and the method of its provision was drafted by the service provider in the competition documentation during the nationwide contractor selection process. All beneficiaries had the opportunity to use exactly the same service (in terms of standard, scope, approach, method of documentation and personnel). Therefore, the analysis could focus only on examining the effectiveness of actions taken by the beneficiaries of these services.

\section{Innovation policy and innovative activity of enterprises}

Innovation policy is a set of elements of science and technology policy. Its goal is to support innovativeness of the economy, i.e. to facilitate introduction of new products, services, technological processes and management techniques [2]. Scientific and technical policy, in turn, is part of the structural policy of the state, establishing the rules governing the development of science and technology and leveraging its results in accordance with the national and social objectives. Since innovations relate to the entire economy, it is recognized that innovation policy should be monitored and coordinated at a high level of national administration. Thus, the innovation process will be interactive and systemic, with contribution to solving social and economic problems as the basic criterion for project selection $[3,4,5]$.

The internal innovation capacity of enterprises and their ability to absorb innovations need not be only alternative ways to achieve the desired level of innovativeness in enterprises. Numerous studies indicate a virtuous circle between both sides of the innovation capacity of enterprises, which are stimulated to openness innovation processes. These include undertaking and developing various forms of cooperation with external partners, aimed at gaining access to sources of new knowledge and skills, as well as complementary resources [6].

Access to external knowledge and other resources and services, as well as their absorption, is becoming an important factor in the effective innovation of enterprises, especially those operating on a smaller scale $[7,8,9]$.

Micro, small and medium-sized enterprises (SMEs) must cooperate with other enterprises and institutions as operating in a network helps overcome their limitations and helps them get involved in jointly solving problems. Supporting entrepreneurship and innovative processes includes the provision of specific services and the development of an economic and social environment that is entrepreneur-friendly and favors independent business operations. Cooperation between enterprises and BEIs significantly impacts competitiveness of these enterprises [10].

Public support for SMEs plays an important role in accessing external services for innovation as it may impact their ability to cooperate, to absorb and introduce innovations, 
and as a result, to impact their level of innovation. The policy of supporting innovative activities of SMEs, however, has faced a huge variety of their innovative behaviors [11-16]. The issue of institutional support for innovative activities in agro-food business requires pointing to the institutional barrier, i.e. the lack of proper order between the basic agro-food business units, which limits the innovation building processes. The functioning of BEIs is of particular importance in the context of diffusion of innovation and implementation of modern farming methods in rural areas. The structure of institutions providing consulting services is extremely diverse, e.g. due to their history, experience, organizational culture, legal form, ownership structure and costs. Some of them provide specialized consulting services as a core business, while for others the services are non-core. The above factors fail to guarantee a uniform approach to the scope and quality of the provided services, despite the resources and potential of these entities. An additional factor that differentiates consulting centers is the attempts to institutionalize and organize the innovation support system to date. Some of them were undertaken under national programs, while others were financed from EU structural programs. Each of the programs and projects offered different support logic, and the objectives of the intervention included either the construction of a regional network, or brand building and promotion, or the implementation of a specific standardized portfolio of services. In addition to Agricultural Advisory Centers, PARP, as part of a pilot project, offered support under the system services of the National Service System (NSS) dedicated to the agri-food sector. The consulting service was defined in the Regulation of the Minister of Economy and Labor of 27 January 2005 (Journal of Laws of 2005 , No. 27, item 221), as part of plans to cover this type of services with system activities supporting their availability under the NSS.

\section{Result}

The conducted research shows that the dominant legal form of enterprises using the proinnovation service was the sole proprietorship. Micro-enterprises dominated in the study group (72\%). The majority of the service clients (61\%) were businesses with an established market position, i.e. operating for over 10 years. Food producers dominated in the structure of the represented industries.

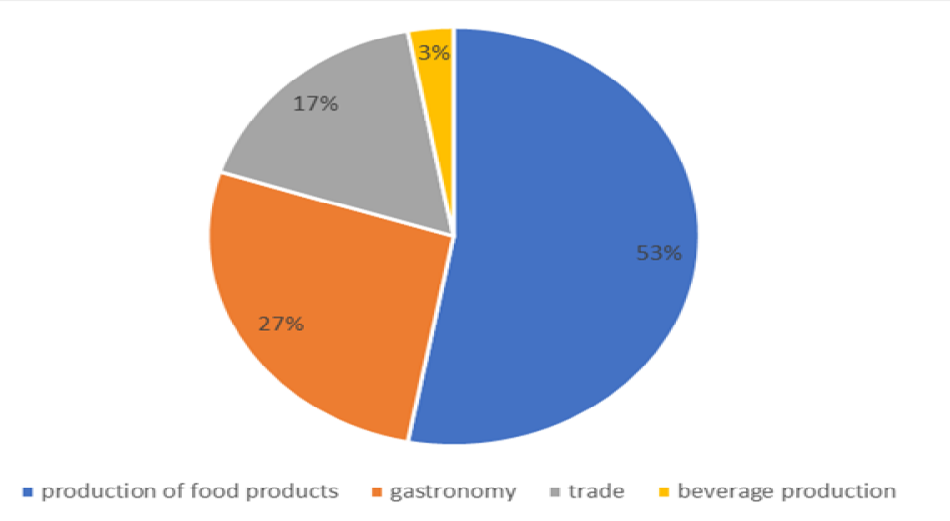

Fig. 1. Client structure by industry.

The analysis of questionnaires showed that $63 \%$ of the service clients were entrepreneurs based in rural areas, and $24 \%$ of entrepreneurs were based in cities with over 100,000 residents. 
The research results indicate that $90 \%$ of all respondents decided to continue the service in question in the second stage of the consulting component, i.e. strategic consulting, which included developing a marketing plan and assisting in its implementation. Only $10 \%$ of respondents resigned from the first component of the pilot service in question after the audit. On the other hand, the second component, i.e. training in marketing and sales for micro and small enterprises in the agri-food industry, was used by $94 \%$ of the surveyed enterprises. These values show that the service was tailored to the needs of entrepreneurs and they thought it worthwhile to participate in its various stages.

The research shows that during the audit, a number of marketing activity areas for improvement were identified in the surveyed companies. There was no situation, in which no recommendation was made in the audit report, which means that the addressees of the service were enterprises with genuine marketing needs. The suitability of the service to the needs of entrepreneurs is also evidenced by the clients' tendency to implement the recommendations. More than half of the surveyed entrepreneurs implemented the majority of actions recommended by service providers.

The general assumption of the publicly financed system service was its suitability to the needs of entrepreneurs. Most companies (87\%) used all components of the pilot service, i.e. audit, consulting and training. The service providing institutions have identified several areas for improvement for their clients. In executive marketing programs, they recommended primarily the actions indicated in the service standard, and their recommendations are to be considered useful for agri-food sector enterprises. Most entities have implemented, or are planning to implement audit recommendations. However, the main problem the enterprises faced at the implementation stage was the lack of adequate financial resources. The same reason was given by the respondents as the grounds for not implementing the recommendation, and for no intention to implement the recommendation in the future. For a small percentage of respondents $(2 \%)$, the reason for not using the consulting service was an effective marketing policy already in place. This indicates that the service was used by clients who had real needs in this area.

\section{Summary}

The research confirmed that there is a niche in the demand for specialized consultancy services in the agri-food sector. Marketing and sales of agri-food products should be cofinanced from public funds as a system service under the NSS. This is due to the suitability of the service to the needs of entrepreneurs, combined with a small propensity of companies to pay in full for this type of service. Moreover, entrepreneurs do not have a qualified personnel who could effectively conduct marketing activities. Attention should also be paid to the low availability of similar services on the market and its highly appreciated comprehensiveness.

The effectiveness of support services provided by BEIs has been identified as one of the most important factors in the innovation policy system that determines the success of innovative projects of the SME sector. At the same time, it should be remembered that this indication is subjective as the evaluators were entrepreneurs participating in the research.

\section{References}

1. Z. Gródek-Szostak, Przegląd Organizacji, 11 (922), 10-15, (2016).

2. E. Stawasz, Innowacje a mała firma, Wydawnictwo Uniwersytetu Łódzkiego, (1999). 
3. A. Szelag-Sikora, M. Niemiec, Jakub Sikora, M.Chowaniak, Farm Machinery And Processes Management in Sustainable Agriculture, X International Scientific Symposium, Lublin, 365-370, DOI:10.24326/fmpmsa.2017.65 (2017).

4. Z. Gródek-Szostak, A. Szeląg-Sikora, J. Sikora, M. Korenko, Business and Non-profit Organizations Facing Increased Competition and Growing Customers' Demands (Eds. A Ujwary-Gil, A Nalepka), Wyższa Szkoła Biznesu - National-Louis University, Nowy Sacz, 16, 427-439, (2017).

5. E. Chyłek, Wieś i Rolnictwo, 3, (2011).

6. M. Cupial, A. Szelag-Sikora, M. Niemiec, Agriculture and Agricultural Science Procedia, 7, 64-69 (2015).

7. K. Mellahi, A. Wilkinson, International Journal of Innovation Management, 4 (2008).

8. Z. Gródek-Szostak, L. Ochoa Siguencia, D. Kajrunajtys, Annals of Social Sciences \& Management Studies 2 (3), 001-005, (2018).

9. Z. Gródek-Szostak, D. Kajrunajtys, L. Ochoa Siguencia. Information Technology as a catalyst of innovative changes in enterprises. Society. Integration. Education. Proceedings of the International Scientific Conference. 6, 169, 177, (2019).

10. J. Sikora, M. Niemiec, A. Szelag-Sikora, M. Kubon, E. Olech, and A. Marczuk, Przemysl Chem. 96, 2275-2278 (2017).

11. B. Dankbaar, Technology Management and Public Policy in the European Union, (Eds. W. Cannell, B. Dankbaar), Office for Official Publications of the Erropean Communieties, Oxford University Press, Oxford, New York (1996).

12. A. Szelagg-Sikora, J. Sikora, M. Niemiec, Z. Gródek-Szostak, J. Kapusta-Duch, M. Kuboń, M. Komorowska, J. Karcz, J. Sustainability,11, 5612, (2019).

13. Z. Gródek-Szostak, G. Malik, D. Kajrunajtys, A. Szelagg-Sikora, J. Sikora, M. Kuboń, M. Niemiec, J. Kapusta-Duch, J. Sustainability, 11, 4144, (2019).

14. J. Kapusta-Duch, A. Szelagg-Sikora, J. Sikora, M. Niemiec, Z. Gródek-Szostak, M. Kuboń, T. Leszczyńska, Borczak B. Sustainability, 11, 4008, (2019).

15. M. Niemiec, M. Komorowska, A. Szeląg-Sikora, J. Sikora, M. Kuboń, Z. GródekSzostak, J. Kapusta-Duch. Sustainability, 11, 3913, (2019).

16. A. Szelag-Sikora, Z. Gródek-Szostak, D. Kajrunajtys. Agricultural Producer Groups as an Example of Commercial Organizations in the Agricultural Sector (Eds. A. Krakowiak-Bal, M. D. Vaverková) Infrastructure and Environment, Springer, 318-324, (2019). 